\title{
Improved performance of hydrodynamic bearings by proactive adjustment
}

\author{
JAMES KeITH MARTIN ${ }^{\mathrm{a}}$ \\ Department of Design, Development, Environment and Materials, Faculty of Mathematics, Computing and Technology, \\ The Open University, Milton Keynes, MK7 6AA, UK
}

Received 23 September 2010, Accepted 14 December 2010

\begin{abstract}
There has been a number of initiatives launched in the field of lubrication as potential sources of improvements in energy efficiency in a wide range of engineering products, plant and processes. Attention is being focussed on bearings to improve both performance and efficiency in fields such as automotive, machine tools, industrial and power generation plant. This paper reviews some of the background to these drives and illustrates how a novel design of adjustable fluid film hydrodynamic journal type bearing shows promise to both improve performance and save energy. Theoretical modelling and practical tests have demonstrated clear improvements over conventional fluid film bearings, along with a number of other characteristics offering benefits that may be of interest to designers and users of such bearings.
\end{abstract}

Key words: Hydrodynamic / journal bearing / adjustable

Résumé - L'exécution améliorée des paliers hydrodynamiques par ajustement dynamique. Un certain nombre d'initiatives a été pris dans le domaine de la lubrification, considéré comme une source potentielle d'amélioration de l'efficacité énergétique dans une vaste gamme de produits d'ingénierie et des procédés. Une attention particulière porte sur l'amélioration des performances et l'efficacité des paliers dans des domaines tels que l'automobile, les machines-outils et les unités de production d'électricité. Cet article dresse un panorama de ces développements et montre comment une nouvelle conception de palier hydrodynamique ajustable s'avère prometteuse à la fois en termes de performances et d'économies d'énergie. Des travaux numériques et expérimentaux ont montré de nettes améliorations de ces paliers par rapport aux paliers traditionnels, avec un certain nombre d'autres caractéristiques présentant des avantages pouvant également intéresser les concepteurs et les utilisateurs de paliers fluides.

Mots clés : Hydrodynamique / palier / ajustable

\section{Introduction and background}

\subsection{Energy considerations}

It has been estimated that from one-third to one-half of the total energy produced in the world is used in overcoming friction. Just considering the vast numbers of rotating parts and industrial plant even very small improvements in lubrication effectiveness and bearing design will have widespread and significant knock-on effects in terms of energy saving. There has been a number of initiatives pursuing this theme. The UK Government sponsored 1966 report by Jost et al. [1] concluded that the potential savings to British industry resulting from lubrication education and research were about $£ 515$ million p.a. (in 2010 terms $£ 7.3$ billion, or $€ 8.9$ billion). A key lecture paper presented in 1981 [2] showed that tribology has a role

\footnotetext{
${ }^{a}$ Corresponding author: j.k.martin@open.ac.uk
}

to play in environmental protection in terms of reducing the production of greenhouse gases and use of nonrenewable energy and raw materials. This was a comprehensive study, and included results and recommendations from other studies carried out for the Federal German and United States Governments, all of which identified the massive consumption of energy spent in overcoming friction and the potential for savings. It also specifically highlighted losses and potential savings in the bearings supporting rotating plant in electrical power generating sets, manufacturing and processing industries. In 1992 the UK Institution of Mechanical Engineers launched a Tribology Action Campaign [3] highlighting potential savings of $£ 1.5$ billion p.a. (in 2010 terms $£ 2.4$ billion, or $€ 2.9$ billion).

It is noteworthy that all these initiatives were presented in times when concerns over energy use and global warming were not the mainstream topics they are now. 
Strictly, energy is not consumed, merely converted from one form to another. In friction and lubrication the energy "lost" or "power absorbed" is accounted for by direct generation and dissipation of low grade heat, perhaps also via a little noise and other irreversible effects such as expulsion of oil mist, wear particles etc. This energy is practically irrecoverable and thus all wasted. Fluid film bearings are not exempt as they operate by the mechanism of viscous shear of the lubricant and so "consume" some energy, even when there is no surface to surface contact. Although relatively small in an individual bearing, on a global scale it is significant as there are literally millions if not billions of bearings in operation at any one moment. For example just considering the estimated number of cars and light trucks in use worldwide at over 800 million there could be 12 or more fluid film bearings in each engine, not counting the big and little end connecting rod bearings (which are subject to a more complicated lubrication regime). This gives as a conservative estimate 9.6 billion fully functioning fluid film journal bearings operating at one time, not counting those in trains, ships, industrial plant etc. Thus there is plenty of scope to address the efficiency of bearings and lubrication in all industrial applications, a point previously made by the author [4,5]. Also echoing this approach Dan Kapp, Director, Ford Powertrain Research and Advanced Engineering, in a keynote speech at the 2010 STLE 65th Annual Meeting \& Exhibition, called on the Lubrication research community to address the reduction of efficiency losses in automotive powertrains, including those due to friction and durability of bearings - chasing "every jewel of energy". At the same meeting Santos and Estupinan suggested that of the friction losses in automotive engines, $23 \%$ were due to those of the bearings and there was scope for addressing this issue in the design of mechatronics control systems to dynamically control hydrodynamic fluid film formation [6]. Fluid film bearings do offer many advantages and are in widespread use in many applications. They are cheap to manufacture, use minimum packaging space, offer significant stiffness and damping when under load, tolerate particles and pollutants in the lubricant which is almost always oil, plentiful and cheap - and can last indefinitely if used correctly. Apart from the energy considerations however there are a couple of other issues associated with them.

\subsection{Accuracy and precision}

A second issue of concern with fluid film journal bearings is the accuracy of location of the rotating centre. By definition there must be a clearance in diametral dimensions between the stationary and rotating members to provide the space for the lubricant to work sufficiently, i.e. to completely separate the two with the fluid film. In a hydrostatic bearing this clearance varies with the load as a necessary condition of providing stiffness. In a hydrodynamic bearing there must be sufficient clearance to allow a convergent shaped space for the lubricant to act in generating the high pressure fields sufficient to carry the applied load. Thus in a loaded fluid film bearing there must always be a small difference or eccentricity between the rotating and bearing axes positions. This could mean for example in a gearbox the possibility of a slight misalignment or out of alignment of meshing gears. If the load itself was dynamically changing in magnitude and direction, the centre of rotation itself would also be moving, within the constraint of the clearance. This in turn could have effects in terms of premature wear or noise of the gears themselves, an aspect investigated by the author [7]. In other applications the lubricant film clearance and its variation under load can impose limits on the accuracy of location of the rotating centre, a further aspect considered by the author [8].

\subsection{Stability}

The third issue associated with fluid film bearings, particularly of the hydrodynamic type, is that of stability at low loads. Under certain circumstances of a low or zero load condition the journal or shaft running in a plain hydrodynamically lubricated bearing may take up a whirling motion, again constrained by the clearance space. The journal centre, i.e. the centre of rotation, itself adopts an approximately circular motion with a speed of half or just under half the speed of journal rotation. A more complex pattern of motion or "orbit" can be stimulated or excited by a superimposed dynamic small load or disturbing force (for example gear tooth engagements or small out of balance forces). This phenomenon has been seen in larger vertical shaft installations in power generating plant when attempting to run at low load outputs, i.e. when there is a low steady load. This instability if not suppressed can cause fluid film breakdown and damage to the bearing surfaces themselves or lead to inaccuracies for example in a machine tool application when on light finishing operations.

\subsection{Previous developments in hydrodynamic journal bearings}

Significant previous developments include producing the lubricant film converging shape by means other than the eccentric displacement and introducing a plurality of pressure fields, as outlined in Figure 1. This shows some ingenious ways to create the hydrodynamic converging wedge shape for the lubricant film without relying totally on the need for the journal to adopt an eccentric rotational centre position. By careful machining of the bearing housing 2, 3, 4 or more converging shapes are built in to the bearing. All of these bearings can offer improvements but at the cost of greater precision machining and assembly. The shapes shown are greatly exaggerated and in reality the wedge profiles would not be noticeable by eye. Another interesting idea has been the use of tilting pads (a.k.a. pivoted shoes in the USA) where each pad is free to adopt its own convergence and provide a pressure field independently of the others. Figure 2 shows the 


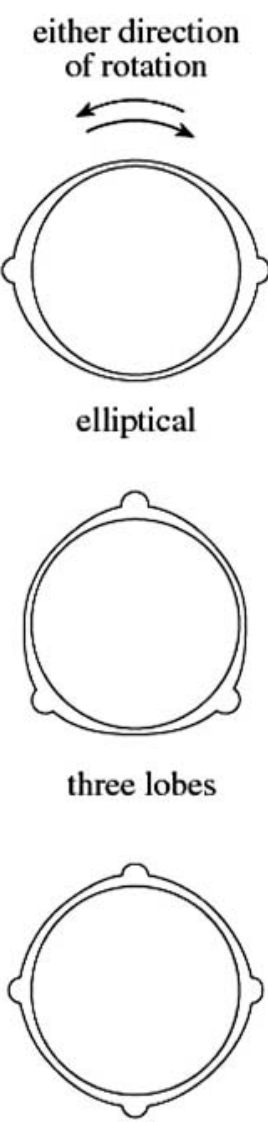

four lobes
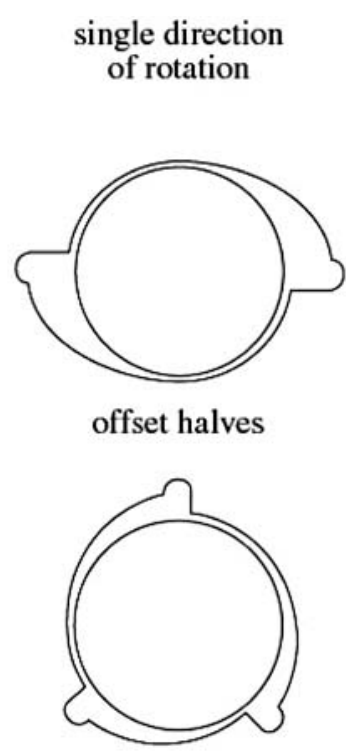

tilted three lobes

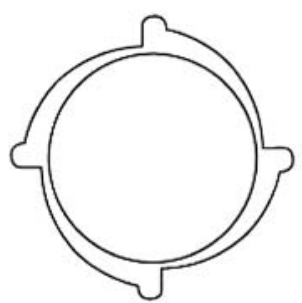

tilted four lobes

Fig. 1. Outline of various profiled bearing schemes.

principle, noting again that clearances and potential tilt movements are greatly exaggerated. In this case there are 4 pads and each pad's pivot is central to cope with a journal that may rotate in either direction. As the journal rotates each pad tilts very slightly and fluid pressure profiles are generated in the lubricant film for each pad.

The fluid pressures on all pads are nearly equal so that a ring of radial forces, one from each pad, tends to centre the journal in the bearing. If the journal is then loaded in a radial direction it will be displaced slightly and the pads will adopt new tilt angles, no longer equal, until the oil film pressure forces balance the new load. For increased effectiveness the pads are mounted with a preset towards the journal, rather than being concentric. For some designs the pad can also pivot in the axial direction to allow a degree of misalignment of journal and bearing axes - important for example in ships' propeller shaft bearings when the vessel may encounter rough water causing hull and shaft strains. One key aspect of the tilting pad bearing is that the pads do not totally embrace the full circumference of the journal. The presence of gaps generally reduces the power absorption because the lubricant film is not being sheared for the full distance around. The tilting pad's efficiency is also increased if the pivoting position of the pad is not central, but with an offset. This is suitable when the direction of rotation is constant.

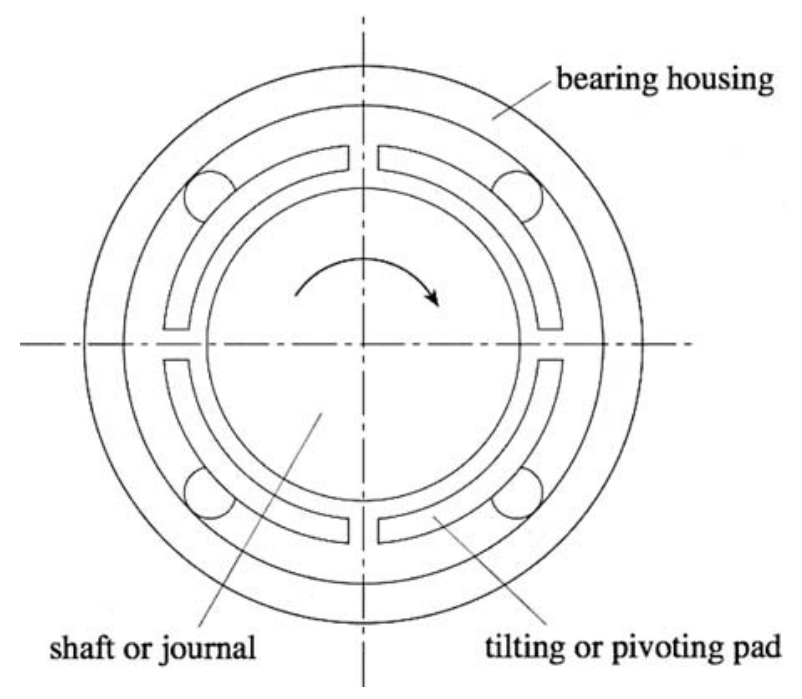

Fig. 2. Outline of tilting pad journal bearing.

All of the bearings as described so far have their advantages and disadvantages in terms of stiffness, damping, and power absorbed, but they are all reactive systems. The converging profiles and consequent pressure fields are generated in response to the operating conditions. That is to say, they react to changes in load or other operating conditions in order to set up an equilibrium stance which balances the applied load. What is needed perhaps is a more proactive bearing system which combines the properties and advantages of the above bearings for any and all given operating conditions. New developments show promise in all these respects.

\section{New developments in fluid film bearings}

\subsection{Active control of bearing pad supports and hydrodynamic pressure fields}

Santos et al. have been investigating methods to increase damping in rotor bearing systems by hydraulic means using pressurised tilting pad supports as a means to adjust clearance, [9]. By means of servo valves, a hydraulic pressure is generated, deforming the flexible support chambers and making the pads move against the bearing oil film. This results in an increase in the overall damping and stability of the rotor-bearing system. An alternative approach [10] was to directly influence the hydrodynamic oil film pressures via a series of orifices in the pad bearing surfaces, thereby modifiying the stiffness and damping of the bearing. This approach is claimed to control the first bending vibration mode of a flexible rotor via its bearings [11].

\subsection{Active control of bearing pad clearance and lubricant film shape}

Work by the author began in 1986 to investigate an idea by the then Cranfield Unit for Precision Engineering 


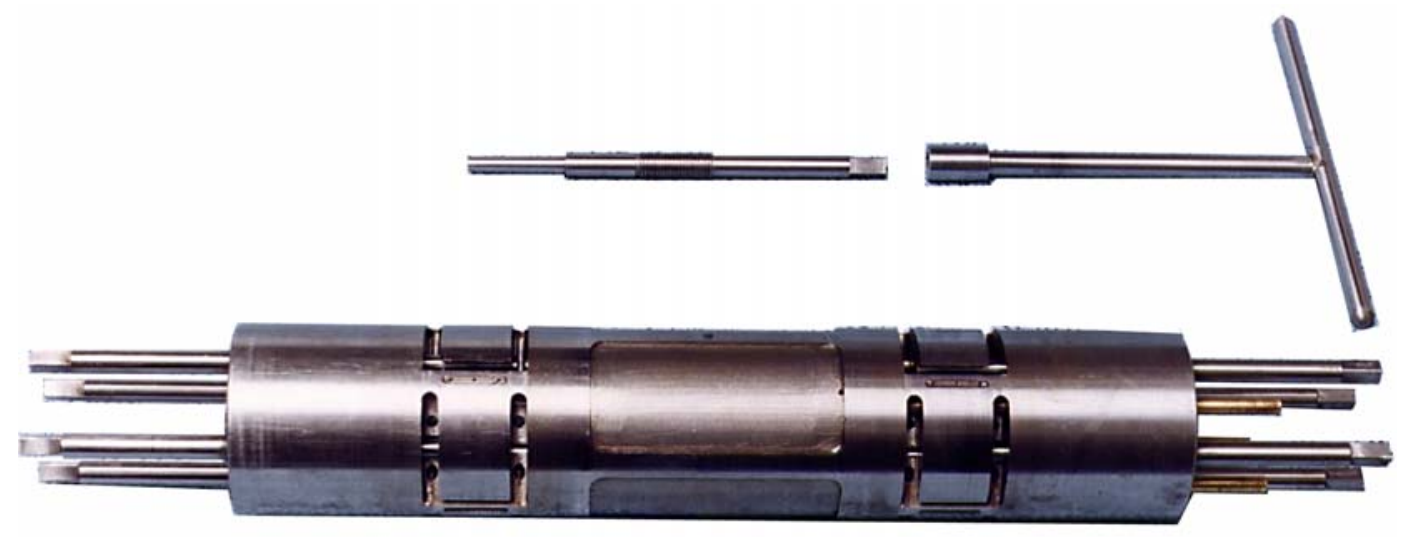

Fig. 3. Adjustable bearing spindle.

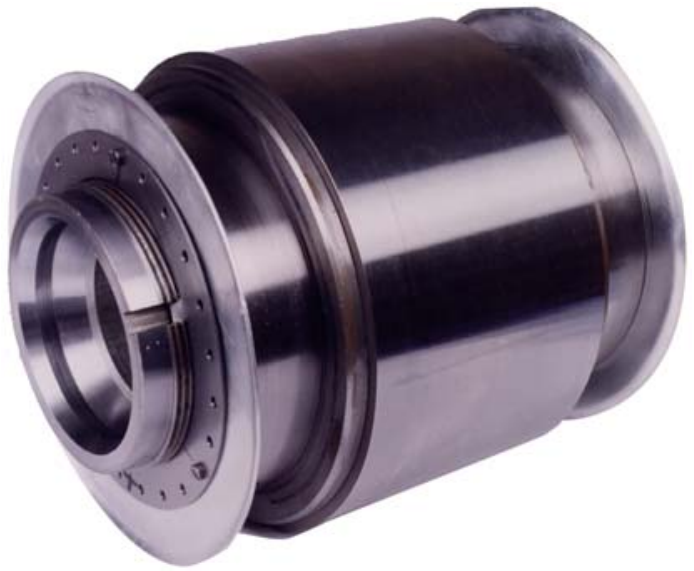

Fig. 4. Bearing rotor.

to design a machine tool spindle as a stationary bearing support for a rotor which contained a grinding wheel. This comprised hydrostatic bearings but it soon became clear that a hydrodynamic component was necessary in view of the speeds and loads envisaged. The author designed an arrangement comprising 2 hydrodynamic bearings "bookending" a central hydrostatic bearing, supporting a belt driven rotor, Figures 3 and 4 . The spindle diameter is $70 \mathrm{~mm}$. Figure 5 shows a cross section of the bearing arrangement.

Importantly, the hydrodynamic bearings each comprised 4 adjustable segments which by the simple means of turning a tapered support pin could be tilted to a predetermined angle irrespective of the load on the rotor and whilst it and the bearings continued to operate. Figure 6 shows the test rig which used a non-contacting means to apply vectored loads to the rotor [12]. The rotating centre could be moved into any position for any given load and just as important a zero eccentricity position could be established and maintained for any given load, and changes in load, by selective adjustments of the hydrodynamic segments. It was also shown that the stiffness coefficients could be changed during operation with other parameters (including load) remaining constant [13].

With experience gained from designing and testing the adjustable rotor bearing and in developing a comprehensive theoretical model [14-16] larger designs of an adjustable bearing were manufactured and tested in a Royal Navy Destroyer gearbox test rig [7]. These supported a pinion shaft of $190 \mathrm{~mm}$ diameter rotating at 1500 rev.min ${ }^{-1}$. Figure 7 shows the 2 bearings tested. Each comprised 4 pads whose attitude could be controlled by adjustable support pins. Figure 8 shows the principle as a longitudinal cross section of one of the pins. As the pin is turned it advances or retracts and hence displaces the pad in the radial direction. The pads of the bearing on the left in Figure 7 each have 1 adjuster and 1 degree of freedom - the pad tilt angle can be adjusted from zero to a positive tilt angle. This is the minimum degree of freedom action required for the adjustable bearing concept to operate. At zero tilt angles the bearing can operate as a conventional hydrodynamic bearing, when adjusted the hydrodynamic characteristics are modified, the convergence angle suiting one direction of rotation.

The pads of the bearing on the right in Figure 7 each have 2 adjusters and 2 degrees of freedom. The pad tilt angle can be adjusted from zero to a positive or negative angle, thereby suiting both forwards and reverse directions of rotation, moreover these pads can also be displaced in a radial direction. Both novel bearings demonstrated the ability to reposition the journal centre of rotation whilst in operation, in any direction, for a range of loads with differing initial adjustment conditions (e.g. full adjustments or zero adjustments). A journal orbit could be provoked at zero load conditions and quickly suppressed with pad adjustments. The size of the journal orbit compared to that of the current bearing could be repeatedly reduced by at least $50 \%$ with both novel bearings for any given load setting, including zero. Figure 9 shows a significant orbit suppression implying a greater degree of stability with the adjustable bearing system. Both novel bearings produced oil temperature rises which were consistently lower than those for the current bearing for comparable conditions for all tests and using the same oil supply system 


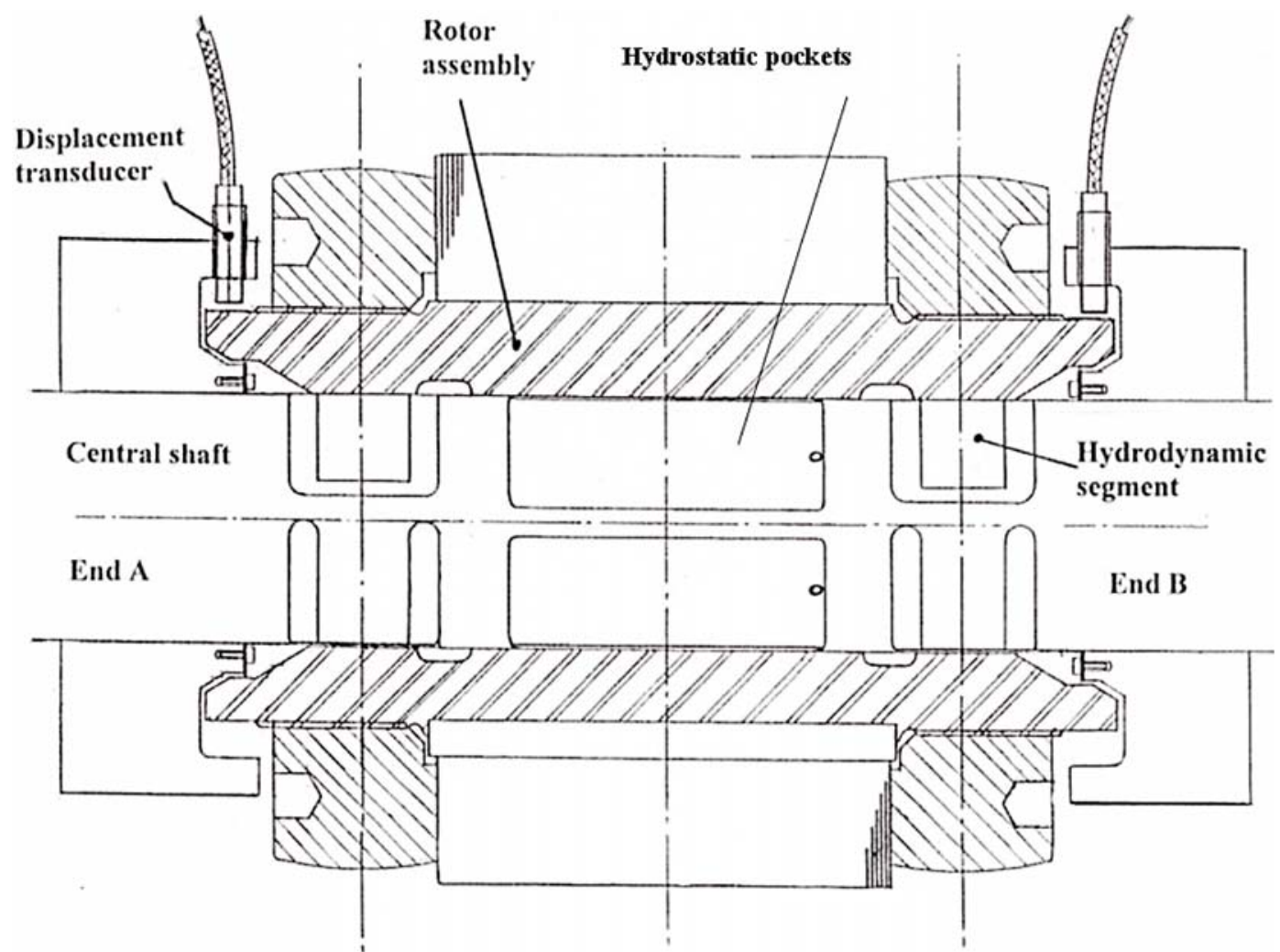

Fig. 5. Rotor bearing scheme.

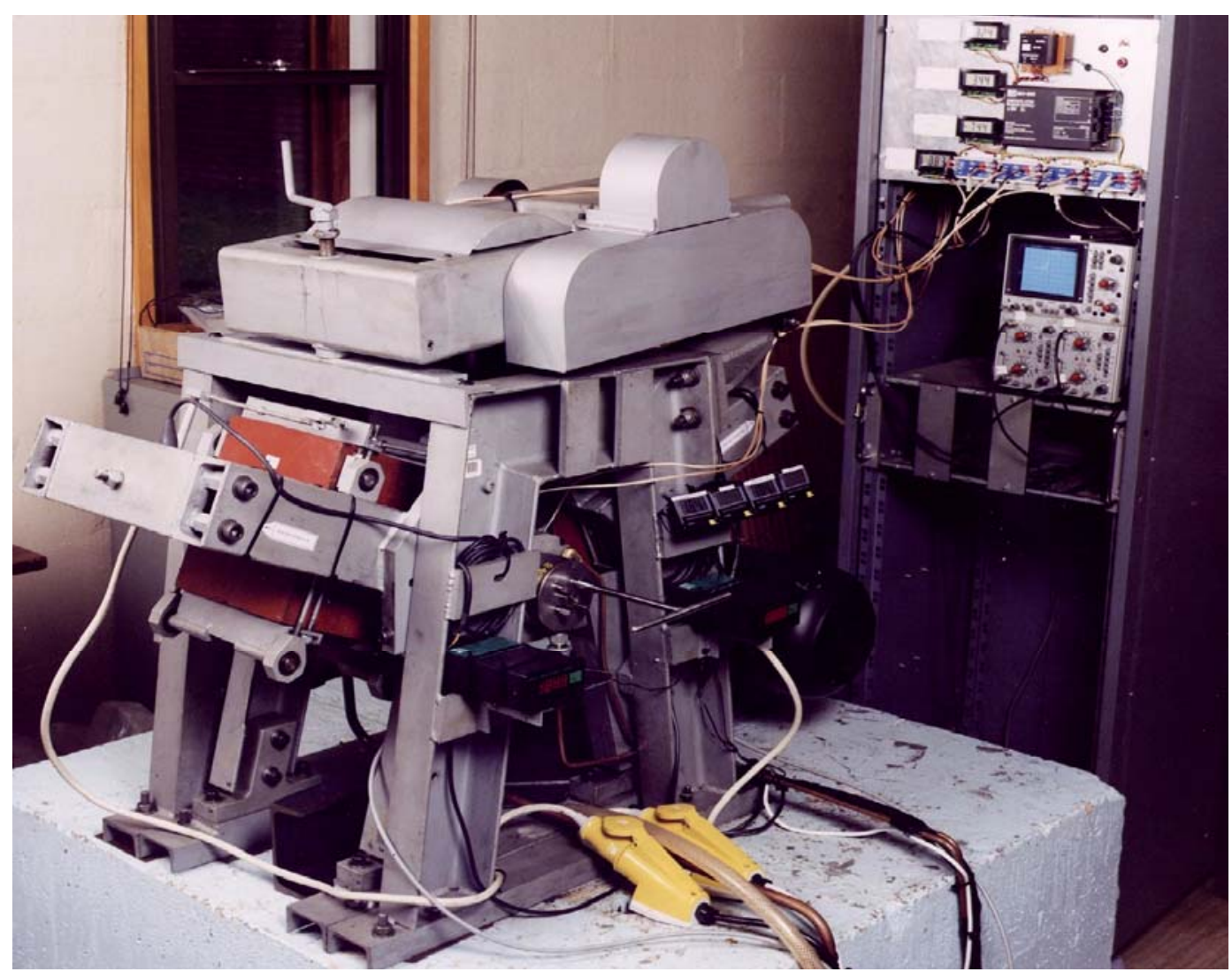

Fig. 6. Adjustable rotor bearing test rig. 


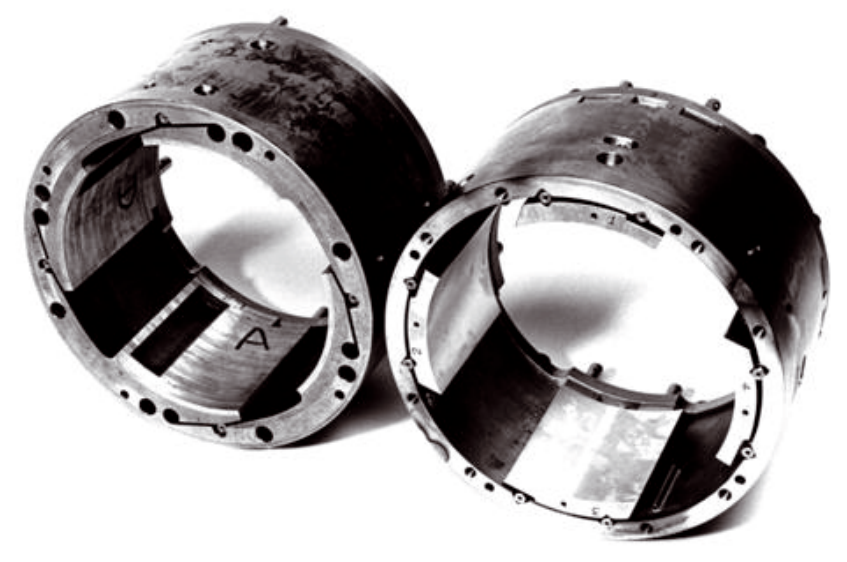

Fig. 7. Large adjustable hydrodynamic bearings.

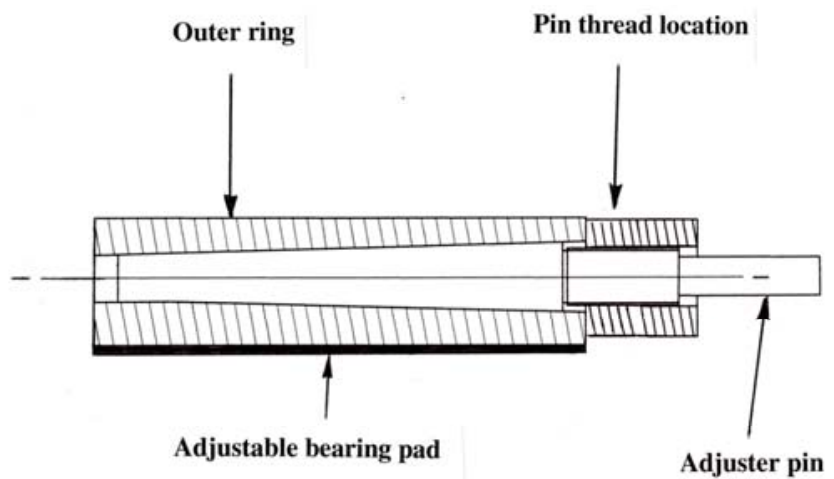

Fig. 8. Pad support adjustment arrangement.

and pressures. The low load stability indicated by both types of bearing reflects that indicated by the theoretical studies of Shenoy and Pai in India [17]. The reduced temperature rises are in accord with experiments carried out by Muhsin [18] with a discretely adjustable bearing where measured fluid film torques were consistently $20 \%$ less than with an equivalent plain bearing, as depicted in Figure 10.

A feasibility study has been carried out for a design of adjustable hydrodynamic bearing for use in a vertical shaft hydro-electric power generation set. This was predominently to address the issue of instability in low output load running conditions. Preliminary calculations, however also indicated that for normal load running a single plant set could save between 14 and 23 GJ energy per day in operation with the adjustable bearing design substituted for the current bearings. This energy would be free to add to the output and the efficiency improvement would mean a daily saving per plant set of 0.9 to 1.5 tonnes of $\mathrm{CO}_{2}$ that would otherwise be generated to make up the difference.

Table 1 summarises the characteristics that have been demonstrated by the concept of adjustable fluid film hydrodynamic bearings as studied by the author, in particular that of proactively adjusting the hydrodynamic fluid film shape. These might be of interest to the designers
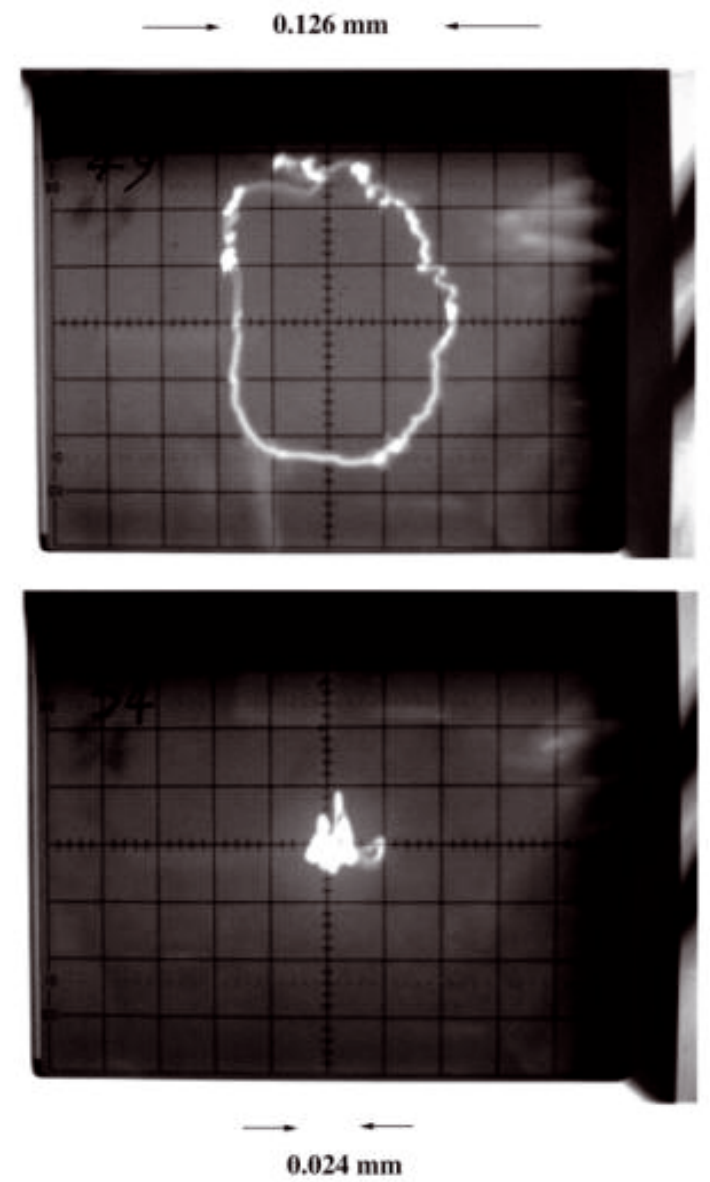

Fig. 9. Journal orbit suppression.

and operators of plant and equipment using conventional designs of fluid film bearing.

\section{Conclusions}

In recent years there have been calls to address the losses of energy in all fields of lubrication. In particular many authorities in industry are calling for improved performance and design of fluid film bearings to save energy and improve accuracy and stability. Studies conducted and reported by groups in Brazil, the UK, the USA, Denmark, France and India are showing agreement on the potential to improve fluid film bearing performance by invoking the concept of proactive adjustment and control of the generation of hydrodynamic lubrication. More work is needed to investigate the performance characteristics of such bearings including mapping all stiffness and damping coefficients, measurements of running torques and power absorbed, and harnessing the latest techniques and systems in the field of mechatronics to design robust accompanying control systems.

Acknowledgements. The author is pleased to acknowledge the support of the Open and Cranfield Universities and 
Table 1. Characteristics of adjustable hydrodynamic bearings.

\begin{tabular}{ll}
\hline Characteristics demonstrated & Potential benefits in applications \\
\hline Reduced power absorbed & Saves energy; important in widespread and/or long running bearings. \\
\hline Greater stability & - Enables operation at low loads. \\
& - Reduced rotor vibration and noise signatures. \\
\hline Reduced lubricant temperature rise & - Less cooling required. \\
& - Higher rotational speeds possible. \\
& - Enables reduced lubricant supply flow rates. \\
\hline Adjustable in operation for: & \\
\hline Stiffness and damping & - Obtain optimum performance over wide speed and load ranges. \\
& - Can change rotor critical speeds/and or pass through critical speed regions quickly. \\
& - Reduce risk of damage caused by vibration. \\
\hline Journal centre location & - Precision applications. \\
& - Maintaining a specified centre of rotation (incl. zero eccentricity) for a range of \\
\hline Loading & loads and speeds. \\
\hline Wear & Equalise loads per pad and/or multi - in line bearings. \\
\hline Lubricant temperature rise & Maintain characteristics over a longer period. \\
\hline & - Higher rotational speeds. \\
\hline
\end{tabular}

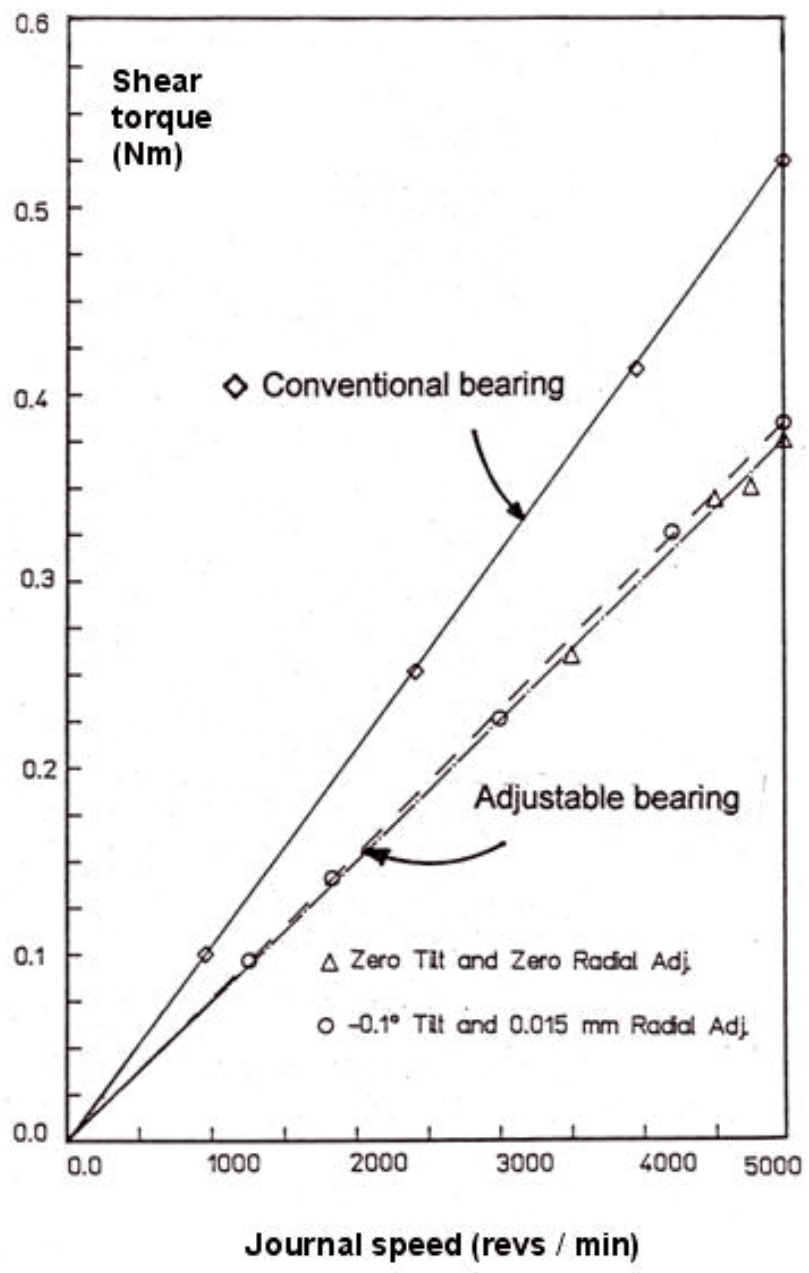

Fig. 10. Measured viscous shear torques for plain and adjustable bearings.

Dr D.W. Parkins in both the theoretical and practical aspects of his work on adjustable hydrodynamic bearings.

\section{References}

[1] H.P. Jost et al., Lubrication (Tribology) Education and research, Report, UK Department of Education and Science, HMSO, London, 1966

[2] H.P. Jost, J. Schofield, Energy saving through tribology: a techno-economic study, Proc. Inst. Mech. Eng., IMechE, London 195 (1981) 151-173

[3] B. Halligan et al., Tribology action campaign source book, ISBN 085298832 X, IMechE, London, 1992

[4] J.K. Martin, Innovative bearings to improve performance and efficiency in industry, Int. J. Performability Eng. 4 (2008) $345-56$

[5] J.K. Martin, Energy savings and improved precision with adjustable hydrodynamic bearings, Proc. STLE 65th Annual Meeting, Las Vegas, 2010

[6] I.F. Santos, E. Estupinan, Three types of active lubrication systems for main bearings of reciprocating engines, Proc. STLE 65th Annual Meeting, Las Vegas, 2010

[7] J.K. Martin, D.W. Parkins, Testing of a large adjustable hydrodynamic journal bearing, Trib. Trans. STLE 44 (2001) 559-566

[8] J.K. Martin, The potential use of new forms of adjustable hydrodynamic bearings in the intelligent monitoring and maintenance of machine accuracies, Proc. International Conference on Intelligent Maintenance Systems, Xi'an, China, ISBN 781099 0144, 2003, pp. 943-950

[9] I.F. Santos, On the adjusting of the dynamic coefficients of tilting - pad journal bearings, Trib. Trans. STLE 38 (1994) 700-706

[10] I.F. Santos, F.H. Russo, Tilting-pad journal bearings with electronic radial oil injection, J. Trib. Trans. ASME 120 (1998) 583-594 
[11] I.F. Santos, R. Nicoletti, A. Scalabrin, Feasibility of applying active lubrication to reduce vibration in industrial compressors, J. Eng. Gas Turbines Power Trans. ASME 126 (2004) 848-854

[12] J.K. Martin, Measuring performance of a novel fluid film bearing supporting a rotor on a stationary shaft, by noncontacting means, J. Multi-body Dynamics, Proc. Inst. Mech Eng. Part K 218 (2004) 143-151

[13] J.K. Martin, D.W. Parkins, Some properties of a continuously adjustable hydrodynamic fluid film bearing, Proc. World Tribology Congress, Mech. Eng. Pub., I. MechE. (1997) 184

[14] J.K. Martin, A Mathematical model and numerical solution technique for a novel adjustable hydrodynamic bearing, Int. J. Numer. Methods Fluids 28 (1999) 845-864
[15] J.K. Martin, D.W. Parkins, Theoretical studies of a continuously adjustable hydrodynamic fluid film bearing, J. Trib. ASME 124 (2002) 203-211

[16] J.K. Martin, Extended expansion of the Reynolds equation, J. Eng. Trib., Proc. Inst. Mech Eng. Part J 216 (2002) 49-51

[17] S.B. Shenoy, R. Pai, Steady state performance characteristics of a single pad externally adjustable fluid film bearing, J. Adv. Mech. Design, Systems, and Manufacturing 2 (2008) 937-948

[18] I.A. Muhsin, Design and evaluation of a novel fluid film journal bearing, Ph.D. Thesis, Cranfield University, UK, 1991 